\title{
Respiratory insufficiency and dynamic hyperinflation after rigid bronchoscopy in a patient with relapsing polychondritis -a case report-
}

\author{
Hyun-Joo Ahn, Jie Ae Kim, Mikyung Yang, and Eun Kyung Lee \\ Department of Anesthesiology and Pain Medicine, Samsung Medical Center, Sungkyunkwan University School of Medicine, Seoul, Korea
}

Relapsing polychondritis (RP) is an uncommon disease that is characterized by inflammation and destruction of cartilaginous structures. When tracheobronchial tree is involved, respiratory obstructive symptoms can occur. A 35-year-old man, with a previous diagnosis of RP, was scheduled for rigid bronchoscopy to relieve dyspnea, caused by subglottic stenosis. After laser splitting of the subglottic web, the spontaneous respiration of the patient was insufficient, and hypercarbia developed progressively even with assisted ventilation. After 20 minutes of aggressive hyperventilation to reduce endtidal $\mathrm{CO}_{2}$ level, sudden extreme tachycardia and hypotension developed. Ventilation rate was reduced and prolonged expiration time was allowed to alleviate a near-tampon status from dynamic hyperinflation. After the hemodynamic status was stabilized, the patient was transferred to the ICU for mechanical ventilation. He received ICU care for 30 days, and now, he was on supportive care on a ward, considering Y stent insertion to prevent luminal collapse from tracheobronchomalacia. (Korean J Anesthesiol 2013; 65: 569-573)

Key Words: Acquired subglottic stenosis, Bronchoscopy, Relapsing polychondritis, Respiratory insufficiency, Tracheobronchomalacia.

Relapsing polychondritis (RP) is a rare autoimmune disease of unclear pathogenesis, and is characterized by recurrent inflammation and destruction of cartilaginous structures of many organs. It presents with multi-organ system involvement, but frequently involves the ears, nasal cartilage, ocular and tracheobronchial trees. If airway involvement is combined, then the symptom is manifested mainly by airway obstruction, and the prognosis is usually poor $[1,2]$. Airway management of this pa- tient will be challenging and can cause fatal complications, such as respiratory failure, complete airway obstruction, and airway rupture. RP, even though rarely encountered by anesthesiologists, is a disease with great potential for life-threatening complications in the operating room. In this patient, we experienced post-procedure respiratory insufficiency and near-tampon physiology during mechanical ventilation in a patient with relapsing polychondritis.

Received: August 17, 2012. Revised: 1st, October 10, 2012; 2nd, October 23, 2012. Accepted: October 23, 2012.

Corresponding author: Mikyung Yang, M.D., Ph.D., Department of Anesthesiology and Pain Medicine, Samsung Medical Center, 50, Ilwondong, Gangnam-gu, Seoul 135-230, Korea. Tel: 82-2-3410-6590, Fax: 82-2-3410-6626, E-mail: anesyang@skku.edu

(c) This is an open-access article distributed under the terms of the Creative Commons Attribution Non-Commercial License (http:// creativecommons.org/licenses/by-nc/3.0/), which permits unrestricted non-commercial use, distribution, and reproduction in any medium, provided the original work is properly cited. 


\section{Case Report}

A 35-year-old man who had a history of RP (66 kg and 168 $\mathrm{cm}$ ) was scheduled for rigid bronchoscopy to relieve of his worsening dyspnea. Preoperative fiberoptic bronchoscopy revealed subglottic stenosis (6 mm in diameter, 70\% narrowing) (Fig. 1), and laser splitting of the subglottic web was planned. Notable physical findings are flabby ears and nose. Preoperative chest tomography showed diffuse narrowing of the trachea $(9.4 \mathrm{~mm}$ in diameter) and main bronchi (7.6 $\mathrm{mm}$ in diameter), in addition to right lower lobe partial atelectasis (Fig. 2).

General anesthesia was induced with propofol (target plasma concentration $5 \mathrm{ug} / \mathrm{ml}$ ) and remifentanil (target plasma concentration $4 \mathrm{ng} / \mathrm{ml}$ ), using a target controlled infusion pump (Or-

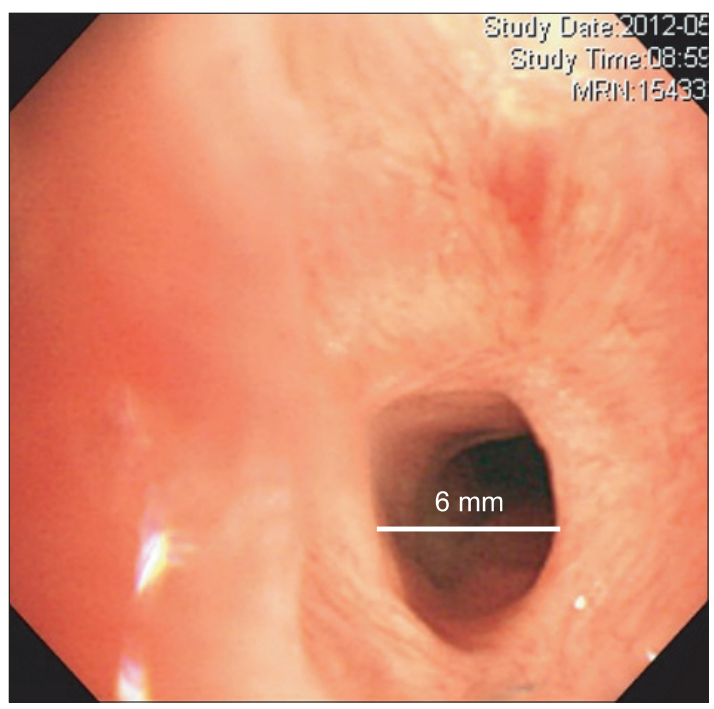

Fig. 1. Preoperative fiberoptic bronchoscopy reveals subglottic stenosis (6 $\mathrm{mm}$ in diameter, $70 \%$ narrowing). chestra IS3, Fresenius Vial, Breezins, France) after injection of lidocaine $40 \mathrm{mg}$. Ninety seconds after injection of succinylcholine $100 \mathrm{mg}$, a rigid bronchoscope was inserted by a pulmonologist. Ventilation was manually assisted with $10 \mathrm{~L} / \mathrm{min}$ of oxygen. In addition to subglottic stenosis, cartilage loss in the entire trachea and airway narrowing, due to luminal collapse, was observed (Fig. 3). Fibrotic band was cut radially by a laser (Fig. 4) and ID 7.5 tube was intubated and placed right above the carina. Total procedure time was about 10 minutes. At the present time, stent insertion was not considered as necessary by the pulmonologist.

Hydrocortisone $100 \mathrm{mg}$ was injected to reduce airway edema by request of the pulmonologist. Although the patient's spontaneous respiration was returned right after the end of the procedure, it was very weak and ineffective. The tidal volume was

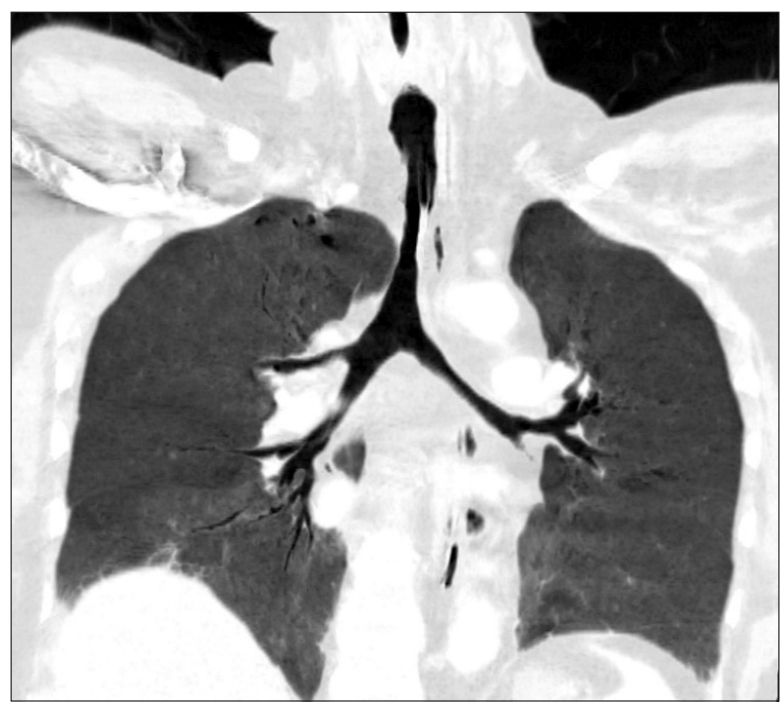

Fig. 2. Preoperative chest tomography shows diffuse narrowing of the trachea (9.4 $\mathrm{mm}$ in diameter) and main bronchi ( $7.6 \mathrm{~mm}$ in diameter), in addition to right lower lobe partial atelectasis.
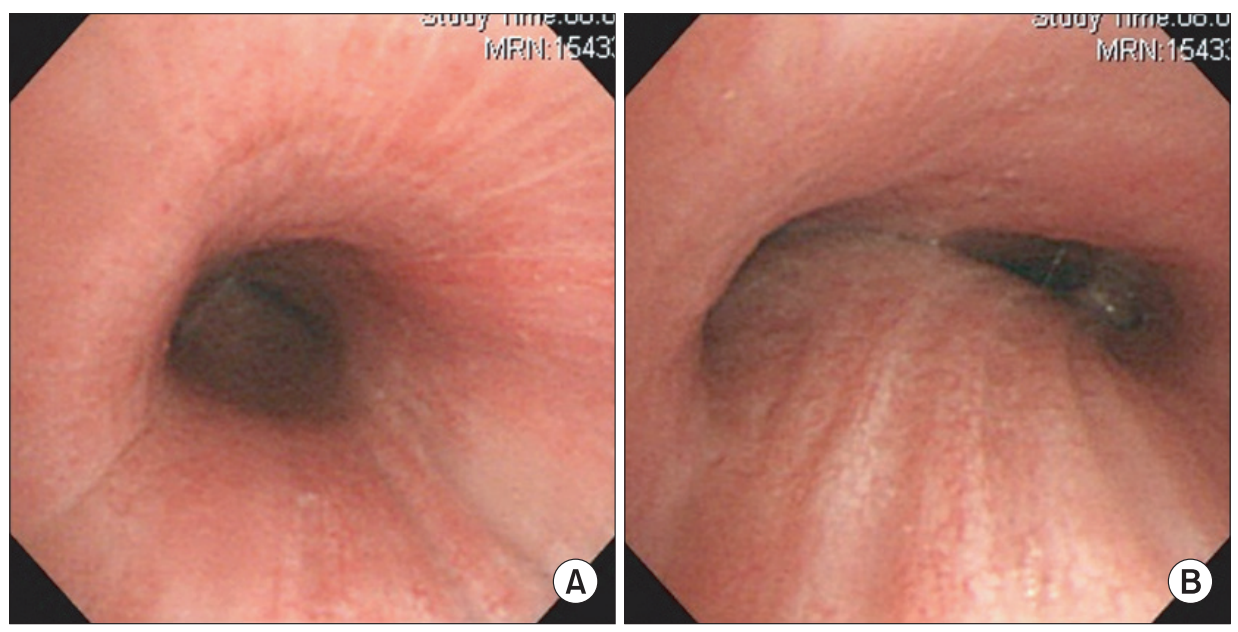

Fig. 3. (A) There is cartilage ring loss in the entire trachea and (B) airway narrowing due to luminal collapse. 


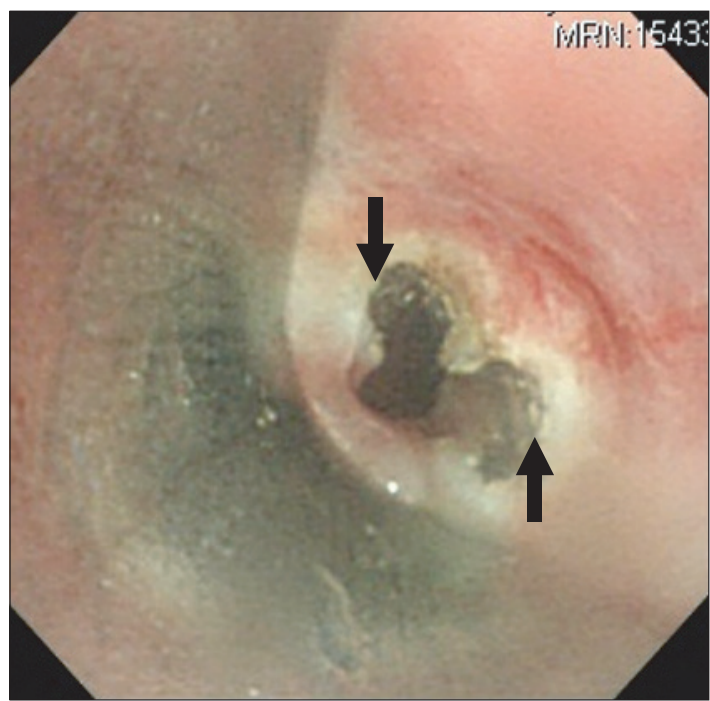

Fig. 4. Fibrotic band in subglottic web is cut radially by laser.

detected as less than $50 \mathrm{ml}$ and assisted ventilation could not augment expiratory tidal volume significantly (50-100 ml). We encouraged the patient to breathe deeply, but there was no improvement of the tidal volume and minute ventilation, and eventually 20 minutes after the return of spontaneous ventilation, end-tidal carbon dioxide $\left(\mathrm{ETCO}_{2}\right)$ level increased gradually from $60 \mathrm{mmHg}$ to $110 \mathrm{mmHg}$. He became irritable with jerky movement of the four limbs, and facial flushing accompanied. His blood pressure (BP) and heart rate (HR) increased to $180 / 110 \mathrm{mmHg}$ and $110 / \mathrm{min}$, respectively. Presuming that the patient's excessive respiratory effort and anxiety could interfere with the effective ventilation assistance, we restarted the infusion of propofol $(2 \mathrm{ug} / \mathrm{ml})$ to sedate the patient. However, the ventilation assistance was still non-effective.

We concluded that the patient was in a state of respiratory failure and recommended the pulmonologist for mechanical ventilation. Waiting for the preparation of ICU bed, the pulmonologist wanted to encourage the patient to breathe in a sitting position after extubation, but the trial was not successful and his $\mathrm{SpO}_{2}$ decreased to $90 \%$. The patient was reintubated with ID 6.5 tube with stylet after an injection of $3 \mathrm{mg}$ of midazolam. Tube was fixed at $24 \mathrm{~cm}$ and breathing sound was generally coarse, and in the right lower lung field, breathing sound decreased more prominently. There was no secretion on suction. After injection of additional $100 \mathrm{mg}$ of succinylcholine, we started hyperventilation to reduce $\mathrm{ETCO}_{2}$ level. In pressure controlled mode (PCV), the setting was pressure above positive endexpiratory pressure (PEEP) $28 \mathrm{cmH}_{2} \mathrm{O}$, PEEP $5 \mathrm{cmH}_{2} \mathrm{O}$, peak inspiratory pressure $33 \mathrm{cmH}_{2} \mathrm{O}, \mathrm{RR} 20 / \mathrm{min}, \mathrm{I}: \mathrm{E}$ ratio $1: 1.5$ and tidal volume was measured as $250 \mathrm{ml}$. $\mathrm{ETCO}_{2}$ decreased from $110 \mathrm{mmHg}$ to $60 \mathrm{mmHg}$ over 20 minutes and $\mathrm{SpO}_{2}$ was well maintained as $100 \%$ at $\mathrm{FiO}_{2} 0.5$.

After 20 minutes of mechanical ventilation, HR increased from $110 / \mathrm{min}$ to $150 / \mathrm{min}$, and BP decreased from 120/70 $\mathrm{mmHg}$ to $80 / 40 \mathrm{mmHg}$ abruptly. On the presumption of near tampon status from dynamic hyperinflation (DHI), we immediately changed the mechanical ventilation into manual ventilation, decreased RR into half, and permitted abundant expiration time after several seconds of apnea period. We could not feel any build-up of high pressure through the reservoir bag. The right radial artery was cannulated for continuous hemodynamic monitoring.

Few minutes after manual ventilation, the patient's hemodynamic status was stabilized (BP 120/70 mmHg, HR $110 / \mathrm{min}$ ). Mechanical ventilation was resumed at different settings to avoid DHI. In PCV mode, the setting was pressure above PEEP $28 \mathrm{cmH}_{2} \mathrm{O}$, no PEEP, $\mathrm{RR} 13 / \mathrm{min}, \mathrm{I}: \mathrm{E}$ ratio $1: 2, \mathrm{FiO}_{2} 1.0$ and tidal volume was measured as $230 \mathrm{ml}$. ETCO 2 was maintained at $60 \mathrm{mmHg}$ without showing further increase or decrease. Ten minutes after resuming mechanical ventilation, arterial blood gas showed pH 7.25, $\mathrm{PaCO}_{2} 75 \mathrm{mmHg}, \mathrm{PaO}_{2} 356 \mathrm{mmHg}$, and $\mathrm{HCO}^{-} 33 \mathrm{mEq} / \mathrm{L}$. We decreased $\mathrm{FiO}_{2}$ to 0.5 and transferred the patient to the ICU. Thirty minutes after ICU admission, arterial blood gas revealed $\mathrm{pH} 7.28, \mathrm{PaCO}_{2} 66 \mathrm{mmHg}, \mathrm{PaO}_{2} 104 \mathrm{mmHg}$, and $\mathrm{HCO}^{-} 31 \mathrm{mEq} / \mathrm{L}$ under the same setting of mechanical ventilation as in the operating room.

During the repeated weaning and extubation failure, his lung condition has aggravated with increased lung infiltrative opacity. He received tracheostomy at postoperative 16th day and on ventilator support for 27 days, postoperatively. In fiberoptic bronchoscopy taken at postoperative 27 th day, generalized tracheobronchomalacia and edematous change were present in the entire trachea and main stem bronchi, and total luminal collapse was observed during coughing or suctioning. He was recommended with Y stent insertion, but refused, and is taking supportive care on the ward.

\section{Discussion}

$\mathrm{RP}$ is a rare autoimmune disease that is characterized by inflammation and destruction of cartilaginous structures [3]. The most commonly involved organs in RP include the ears (85\%), nose (62\%), eyes (54\%), joints (50-75\%), and airways (50\%) [4].

This patient had flabby ears and nose because of cartilage destruction, but no saddle nose deformity. Other involved organs in this patient were eyes (scleritis), joints (rib fracture, sternal fracture, and Achilles tendon rupture), and tracheobronchial tree (dyspnea).

In this patient, respiratory symptoms are the first manifestation of RP. Airway involvement is among the most serious manifestations of RP [5]. Symptoms include hoarseness, a non- 
productive cough, and tenderness over the larynx and proximal trachea. Mucosal edema, strictures, and/or cartilage collapse may cause stridor and life-threatening airway obstruction necessitating tracheostomy. When the involvement extends into the lower airways, it will result in tracheobronchomalacia, which requires stenting. Bronchial cartilage collapse can lead to pneumonia and respiratory insufficiency [4]. This patient already had right lower lobe partial atelectasis before rigid bronchoscopy.

When this patient had visited our hospital, due to hoarseness and cough 8 years ago, a diagnosis of RP had been made on the basis of the typical clinical features, such as diffuse airway narrowing on computed tomography (CT), scleritis, and vestibular neuritis [3]. Neck CT demonstrated significant concentric wall thickening in the entire tracheal airway and luminal narrowing in laryngeal airway. CT scanning is a good tool to evaluate the thickness of the airway wall and can point where the flowlimiting site is occurring, providing help in the choice of therapy [4].

RP patients with airway involvement have ventilation impairment and abnormal pulmonary function test $[6,7]$. In this patient, forced expiratory volume in 1 second is $2.23 \mathrm{~L}$ ( $57 \%$ of predicted value), forced vital capacity is $4.58 \mathrm{~L}$ (94\%) and the ratio is $49 \%$, showing moderate obstructive pattern.

This patient had visited emergency room several times due to aggravating dyspnea. Usually, the dyspnea may be caused by subglottic or regional fixed narrowing, dynamic obstruction, or any combination of these. Early in the disease, there is airway inflammation and edema causing stenosis. Later, as the inflammation subsides, the cartilage structure is lost and the airway collapses. Hence, the fixed pattern might occur early in the disease and the variable patterns later [8]. Without adequate treatment, respiratory tract involvement can be complicated by airway collapse, which is the main cause of death in RP, accounting for almost $30 \%$ of mortality [3].

This patient had combinations of fixed narrowing due to subglottic stenosis, and dynamic obstruction due to airway collapse. Therefore, widening of subglottic stenosis alone could not improve his dyspnea, and the remaining malacia component might cause postoperative respiratory insufficiency. However, the pulmonologist decided not to insert a stent at this time, after considering the risk-benefit ratio. Diffuse airway involvement precluded effective stenting and only introduced complications. Major complications with stent placement are migration, pneumothorax, persistent cough, retained secretions, infection, hemorrhage, and formation of granulation tissues [9]. Most important thing in stent placement is choosing the location at which the stents will do the most good [10]. However, in case of diffuse involvement, as in this patient, the effect of stenting would not outweigh the risk of complications [11].

Dyspnea could be aggravated when supine, presumably due to airway collapse [9]. Therefore, this patient tried to encourage breathing with sitting position, but not effective in this case.

When extreme tachycardia and hypotension occurred abruptly, we auscultated the lung sound to eliminate the possibility of tension pneumothorax. There was no change of breathing sound, compared to that of the previous auscultation after intubation, and subcutaneous emphysema was not observed. The sudden hemodynamic change was coincided with injection of $50 \mathrm{mg}$ of rocuronium, suggesting the possibility of anaphylactic reaction. However, there were no urticaria or erythema on inspection and increase of airway pressure, and desaturation did not happen. Therefore, we presumed that the near-tampon status was provoked from dynamic hyperinflation (DHI) by expiratory air trapping due to high inspiratory pressure, luminal collapse, rapid RR, and decreased I : E ratio [12]. Primary concern in central airway obstruction is not the limitation of inspiratory air flow, but rather DHI with hypercarbia and hemodynamic collapse [9]. CT of the upper airway can be normal in patients with malacia component only. Flow-volume loop and bronchoscopy can be useful in demonstrating the presence of a severe fixed stenosis and illustrating dynamic airway closure on inspiration and expiration [6].

We observed DHI in a RP patient, but usually, DHI can be occurred in COPD (such as asthma or emphysema) patients when they are not allowed sufficient expiratory time during controlled ventilation. Hyper-inflated lungs due to air trapping result in tamponading constrictive force to the right heart. Conacher referred this phenomenon to anesthesiologist applying a tourniquet to the right heart [13]. In this situation, signs of bulging of the external jugular vein and pulsus paradoxus, in addition to the hemodynamic instability can be observed. If there is an immediate improvement of hemodynamics, $\mathrm{O}_{2}$ saturation, and airway pressure after disconnecting the ventilator, diagnosis of DHI could be justified. If there is not any other explanation, except DHI, then disconnecting the ventilator or stopping ventilation may be lifesaving. In resuming ventilator setting after crisis resolving, the key factor is to maximize expiratory time by increasing I : E ratio and lowering respiratory rate. Generally, PEEP is not recommended in patients with severe airflow obstruction [14].

In conclusion, rigid bronchoscopy of RP patient with airway involvement can be complicated with DHI and post-procedure respiratory insufficiency. Therefore, close communications with pulmonologist and a clear understanding of the degree and type of airway involvement are essential to safe anesthetic management. 


\section{References}

1. Sung CH, Park JH, Lim SJ, Choi YW. Relapsing polychondritis with subglottic stenosis diagnosed after tonsillectomy. Korean J Anesthesiol 2008; 54: 459-63.

2. Jeong SW, Hong SH, Kwak SH, Chung SS, Jeong CY, Im WM. Relapsing polychondritis diagnosed after stellate ganglion block. Korean J Anesthesiol 1999; 36: 1087-90.

3. McAdam LP, O’Hanlan MA, Bluestone R, Pearson CM. Relapsing polychondritis: prospective study of 23 patients and a review of the literature. Medicine (Baltimore) 1976; 55: 193-215.

4. Letko E, Zafirakis P, Baltatzia S, Voudouri A, Livir-Rallatos C, Foster CS. Relapsing polychondritis: a clinical review. Semin Arthritis Rheum 2002; 31: 384-95.

5. Chang SJ, Lu CC, Chung YM, Lee SS, Chou CT, Huang DF. Laryngotracheal involvement as the initial manifestation of relapsing polychondritis. J Chin Med Assoc 2005; 68: 279-82.

6. Burgess FW, Whitlock W, Davis MJ, Patane PS. Anesthetic implications of relapsing polychondritis: a case report. Anethesiology 1990; 73 570-2.

7. Faul JL, Kee ST, Rizk NW. Endobronchial stenting for severe airway obstruction in relapsing polychondritis. Chest 1999; 116: 825-7.

8. Mohsenifar Z, Tashkin DP, Carson SA, Bellamy PE. Pulmonary function in patients with relapsing polychondritis. Chest 1982; 81: 711-7.

9. Staats BA, Utz JP, Michet CJ Jr. Relapsing polychondritis. Semin Respir Crit Care Med 2002; 23: 145-54.

10. Sacco O, Fregonese B Oddone M, Verna A, Tassara E, Mereu C, et al. Severe endobronchial obstruction in a girl with relapsing polychondritis: treatment with Nd YAG laser and endobronchial silicon stent. Eur Respir J 1997; 10: 494-6.

11. Lin YT, Zuo Z, Lo PH, Hseu SS, Chang WK, Chan KH, et al. Bilateral tension pneumothorax and tension pneumoperitoneum secondary to tracheal tear in a patient with relapsing polychondritis. J Chin Med Assoc 2009; 72: 488-91.

12. Rogers PL, Schlichtig R, Miro A, Pinsky M. Auto-PEEP during CPR. An "occult" cause of electromechanical dissociation? Chest 1991; 99 : 492-3.

13. Conacher ID. Dynamic hyperinflation - the anaesthetist applying a tourniquet to the right heart. Br J Anaesth 1998; 81: 116-7.

14. Myles PS. Pulmonary transplantation. In: Thoracic anesthesia. 3rd ed. Edited by Kaplan JA, Slinger PD: Philadelphia, Churchill Livingstone. 2003, pp 300-1. 